\title{
Benchmarking Stem Cells and Transplantation in Psoriasis
}

Damiani G ${ }^{1,2,3^{*}}$, Berti E², Pigatto $\mathrm{PDM}^{3}$, Franchi $\mathrm{C}^{3}$, Asa'ad F${ }^{4}$, Fiore $\mathrm{M}^{5}$, Colombo $\mathrm{D}^{6}$, Gronchi $\mathrm{S}^{6}$, Malagoli $\mathrm{P}^{7}$ and $\mathrm{Piccinno}^{8}$

${ }^{1}$ Study Center of Young Dermatologists Italian Network (YDIN), GISED, 24122, Bergamo, Italy

'Dipartimento di Fisiopatologia Medico-Chirurgica e dei Trapianti, Universita' degli Studi di Milano, Unita' Operativa di Dermatologia, IRCCS Fondazione Ca' Granda, Ospedale

Maggiore Policlinico, 20122, Milano, Italy

${ }^{3}$ Clinical Dermatology, Department of Biomedical, Surgical and Dental Sciences, IRCCS Galeazzi Orthopaedic Institute, University of Milan, 20126, Milan, Italy

${ }^{4}$ Department of Biomedical, Surgical \& Dental Sciences, University of Milan, 20122, Milan, Italy

${ }^{5}$ Department of Women, Child and General and Specialized Surgery, University of Campania "Luigi Vanvitelli", 80138 Naples, Italy

${ }^{6}$ Study Center of Young Dermatologists Italian Network (YDIN) and Private practice, via Livigno, Milan

${ }^{7}$ Unit of Dermatology, Azienda Ospedaliera San Donato Milanese, Milan, Italy

${ }^{8}$ Servizio di Fotoradioterapia, IRCCS Fondazione Ca' Granda, Ospedale Maggiore Policlinico, 20122, Milano, Italy

\begin{abstract}
Psoriasis is a chronic systemic inflammatory disease with several abnormalities in hematopoiesis. During the last 30 years, stem cell science was intensively studied, also in the field of psoriasis, to discover therapeutic modalities by reversing the unbalance in lymphopoiesis. In fact, available results in literature have reported psoriasis remission after stem cell transplantation. The present review summarizes the current knowledge on psoriasis, stem cells and transplantation.
\end{abstract}

Keywords: Psoriasis; Transplantation; Stem Cells; Inflammation; Skin

\section{Psoriasis}

Psoriasis is a chronic inflammatory disease characterized by scaling, infiltrating, erythematous and large edges desquamating lesions that are well defined [1-3]. Despite the reported prevalence of $3 \%$ in general population, pathogenesis of psoriasis still remains incompletely understood [4]. An increased body of evidence has linked psoriasis to several comorbidities affecting different tissues, other than skin, such as: lungs, cardiovascular and digestive systems [5-7]. Although psoriasis is easily diagnosed by clinical examination, the associated comorbidities still need less invasive, diagnostic instrumental approaches $[8,9,10]$. More understanding of psoriasis predisposing is achievable by investigating the inflammatory microenvironment, in which stem cells seem to play a key role. In fact, various reports and studies during the last 10 years pointed out that: a) several abnormalities in stem cells are present in psoriatic patients, b) the beneficial role of stem cells transplantation, suggesting the possibility of bone-morrow transplantation as future therapeutic modality to definitively cure the disease in refractory cases [11-14]. In this context, the present review aims to summarize the current knowledge and evidence regarding stem cells, their transplantation \& applications in animal models and future perspectives on their therapeutic role in psoriasis.

\section{Stem Cells in Psoriasis}

Sharpe \& Ferguson (1988) were the first to suggest the role of stem cells in psoriasis [15], concluding that embryonic cells from the palate could differentiate through mesenchymal soluble factors and extracellular matrix molecules. The authors suggested that an unbalance of these signalling molecules might lead to cancer and autoimmune conditions such as psoriasis.

By analysing the genetic profile of stem cells from psoriatic patients, Campanati et al. [16] highlighted a similar imbalance between the Th1/Th17 and Th2 pathways commonly found in blood and skin samples [16]. Furthermore Charruyer et al. [17] described in both murine model and humans that the psoriatic stem cells increase the rate of asymmetric cell division in an IL-17A dependent manner [17]. These findings might suggest that stem cells could play a key role in the initiation and maintenance of psoriasis.

\section{Embryonic stem cells (ESCs)}

Embryonic stem cells (ESCs) are immortal cells that comprise the basal layer of the epidermis. Upon stimuli, ESCs into self-renewing cells and transient amplifying cells (TAs) which undergo differentiation after some other divisions, even if they have a limited proliferative capacity [14]. Characteristically, the epidermis overproliferates in psoriasis, leading to an increased turnover rate up to 5 times [4]. Inflammatory microenvironment and genetic susceptibility are manifested in altered ESCs and TAs phenotypes. In particular, Keratin $1 /$ Keratin $10^{-}$and $\beta 1$ - Integrin ${ }^{+}$profiled cells, namely both ESCs and TAs, showed an increased rate of division [18], confirmed by an overexpression of fatty-acid binding protein 5 (FABP5) and Nestin, representing TAs and ESCs, respectively [19]. Consequently, psoriatic-epidermis hyperplasia is a result of an increase in ESC/TA compartment due to TH17 related cytokines, such as Interleukin (IL) -17 and IL-22 [19].

\section{Dermal-Mesenchymal Stem Cells (dMSCs)}

Dermal-Mesenchymal Stem Cells (dMSCs) are multipotent stem cells with angiogenic ability, despite the fact that they might differentiate into chondrocytes, adipocytes and osteoblasts [20]. dMSCs are capable of full interaction with existent microenvironment and may develop into two main phenotypes: a pro-inflammatory (dMSC1) and antiinflammatory (dMSC2) ones. The former phenotype is characterized

*Corresponding author: Damiani Giovanni, Young Dermatologists Italian Network (YDIN), Study Center of the italian Group for Epidemiologic Research in Dermatology (GISED), 24122, Bergamo, Italy, Tel: +390352278719-720; Fax: +390352278673; E-mail: dr.giovanni.damiani@gmail.com

Received February 27, 2018; Accepted March 12, 2018; Published March 29 2018

Citation: Damiani G, Berti E, Pigatto PDM, Franchi C, Asa'ad F, et al. (2018) Benchmarking Stem Cells and Transplantation in Psoriasis. J Stem Cell Res Ther 8: 416. doi: 10.4172/2157-7633.1000416

Copyright: (c) 2018 Damiani G, et al. This is an open-access article distributed under the terms of the Creative Commons Attribution License, which permits unrestricted use, distribution, and reproduction in any medium, provided the original author and source are credited. 
by the activation of nuclear factor Kappa-light Chain Enhancer of Activated B cells (NFB)-p38, Mitogen Activated Protein Kinase (MAPK) and Jun N-Terminal Kinase (JNK) signaling pathways upon the stimulation of Toll like Receptor (TLR) 4 by lypopolysaccaride (LPS) or Th1 related cytokines.

As for the latter, it is characterized by the activation of Phosphatidylinositol-4-5biphosphate 3-kinase (PI3K- $\alpha$ ), Signal transducer and activator of transcription-1 (STAT-1) signaling pathways upon the stimulation of TLR-3 by double strand RNA [21].

Although the released spectrum of cytokines is different, IL-4 is regulated through the activation of (RANTES) which is expressed and secreted by normal T-cells. Activation can be also through C-C Motif Ligand (CCL)-10, IL1-Receptor Antagonist (RA), Macrophage Inflammatory Protein-1(MIP-1), C-X-C Motif Ligand (CXCL)-9, CXCL10 for MSC1, in comparison to IL-6, IL-8,IL-10, Indoleaminepyrrole 2,3-dioxigenase (IDO) and Prostaglandin E-2 (PEG2) for MSC2 [21]. While MSC2 actively suppresses T cell proliferation and permits proliferation of regulatory T cells (TREGS), MSC1 seems to be involved in establishing and maintaining the pro-inflammatory microenvironment in psoriasis [22]. Furthermore, this type of stem cells plays an active role in establishing the inflammatory microenvironment through pro-inflammatory cytokines, by promoting angiogenesis by secreting Vascular Endothelial Growth Factor (VEGF) and Hypoxia Inducible Factor (HIF)-1a [23]. The angiogenic-related profile has been thoroughly investigated, describing an increased Angiopoietin, Angiomatin, Neuropilin-2, Vasohibin-1 with a reported decrease in Insulin-like Growth Factor-binding Protein (IGFBP)-5 and Globin Transcription Factor 6 (GATA-6) [24,25]. In fact, dMSCs increase the transcription of miRNA-55 and inducible Nitric Oxide Sintetase (iNOS), upon pro-inflammatory stimulation. Conversely, subcutaneous injection with allogenic extracellular Superoxide Dismutase (SOD3)transduced MSCs was able to prevent psoriasis like eruption in Imiquimod-treated mice [26].

\section{Bone marrow Hematopoietic Stem Cells (BmHSCs)}

Bone marrow hemaopoietic stem cells (BmHSCs) are multipotent stem cells that give origin to all peripheral immune cells. Recently, few studies have underlined abnormalities in BmHSCs with a hypothesis that psoriasis might be a result of an altered haematopoiesis [27]. In a fact, Zhang and colleagues described an alteration of the normal hematopoietic system characterized by an increased release of Stem cell factor (SCF) and Granulocyte- Colony Stimulating Factor (G-CSF), IL6, with decreased levels of IL-3, IL-8, LIF, Epidermal Growth Factor (EGF), Hepatocyte Growth Factor (HGF), PDGF, VEGF, IL-1 $\alpha$, IL-1 $\beta$, TNF- $\alpha$ [27]. Nevertheless, no differences were reported in the Cytokine levels in supernatants of incubated bone marrow cluster differentiation (CD) $-34^{+}$mononuclear cells, whether in psoriatic patients, aborted fetuses or normal subjects [28]. Both, genetic and biological profiles were further screened revealing an aberrant activity of bmHSCs with an increased apoptotic behavior [29]. In 2014, Zhang and colleagues reported an overexpression of a differentiation marker of bone marrowderived T-cell progenitor in psoriatic BmHSCs and that this marker maintained higher levels also in peripheral blood cells (PBCs), which were correlated to the severity of the disease [30]. These findings strengthened the theory on the relation between psoriasis abnormalities and hematopoiesis.

\section{Xenotransplantation Model of Psoriasis}

Despite the great importance of drug-induced and genetically engineered mouse models in psoriasis, these models still do not replicate the immunological dynamics and microenvironment in humans, including stem cells [31]. Thus, more attention has grown towards xenotransplantation models due to their use of human tissues, which allows the study of the exact inflammatory microenvironment [32]. The two main xenotransplantation models are SCID and AGR129 mice [33].

SCID mice are mutant mice of the mouse strain CB-17, an $\operatorname{IgH}^{\mathrm{b}}$ congenital partner of the BALB/c $\left(\mathrm{H}-2^{\mathrm{d}}\right)$ mouse [33]. The mutation is autosomal recessive and localized in the centromere region of Ch16. The mutation involves SCID gene, a gene that encodes for DNA breaking repair enzyme and VDJ rearrangement [33]. This genetic defect results in the production of dysfunctional $\mathrm{T}$ and $\mathrm{B}-$ lymphocytes [32]. Such mice may be reconstructed with a xenograft of pre-psoriatic skin and a transfer of activated autologous $\mathrm{T}$ cells [33]. However, these mice present two main defects: a) mature natural-killer cells limit the grafting acceptance, $\mathrm{b}$ ) the need to inject immunocytes or $\mathrm{T}$ cells into the graft to convert healthy skin into a diseased one, which is inadequate to observe early events in pathogenesis of psoriasis [32].

AGR129 mice are RAG-2(-)/(-), which lead to impairment in B and T lineages, and deficiency of IFN- $\alpha$ and $\gamma$ that negatively affect NK response [32]. No injections of cells in the graft are mandatory, making this model adequate to study the early events that characterize pathogenesis of psoriasis [33]. Summary of both mice models are represented in Table 1.

\section{Organs Transplantation and Stem Cells Transplantation}

Although the real incidence of psoriasis, post-transplantation, is still matter of discussion, a recent retrospective study, named EUROCORD, reported that 726 cord blood transplanted patients developed at least one autoimmune disease $(\mathrm{AD})$ and only $2(0,003 \%)$ had psoriasis [34]. Within the first year, the rate became $5.5 \%$ and increasing up to $6.6 \%$ within the second year of follow-up [34]. Interestingly, ADs were more frequent among younger patients at least after 212 days of cord blood transplantation [34]. Despite the large number of patients in this study, another report described an incidence of post-organ-transplant psoriasis of $0.06 \%$ in patients that have experienced adverse events in follow-up visits after transplantation [35]. It was reported that $1 \%$ of the donors had psoriasis exacerbation [35]. However, all these studies did not take familiarity for psoriasis into consideration, when the post-transplantation psoriasis was assessed, taking into account that psoriasis has a high prevalence in normal population. Nonetheless, the previously mentioned studies might not represent the real risk of psoriasis in recipients. Psoriasis and its variant forms (erytrodermic, pustular, plaques) were reported to be elicited or exacerbated by transplantation, although sometimes resolved [36,37]. Few reports and case series described a stable remission with a follow up ranging from 6 to 120 months [14,38]. A comprehensive review was performed by Kaffenberger et al, describing that in HSCs allogenic transplant, 10 out of 13 subjects experienced a complete remission, in comparison to only 1 out of 6 with autologous transplants [13]. Despite this data, the hypothesized pathogenesis is yet to be elucidated.

\section{Therapies for Psoriasis in Solid Organ Transplant Recipients (SOTR)}

Current literature on psoriasis in SOTRs is comprised mainly of case reports, with an absence of systematic clinical research, all of which limit the presence of high-level scientific evidence in this arena. 
Citation: Damiani G, Berti E, Pigatto PDM, Franchi C, Asa'ad F, et al. (2018) Benchmarking Stem Cells and Transplantation in Psoriasis. J Stem Cell Res Ther 8: 416. doi: 10.4172/2157-7633.1000416

Page 3 of 4

\begin{tabular}{|c|c|c|c|}
\hline Xenotransplantation Model & Type of Mutations & Injection of Cells & Characteristics \\
\hline SCID Mice & $\begin{array}{l}\text {-Autosomal Recessive Mutation } \\
\text {-Defect in SCID Gene } \\
\text { - Defect in VDJ arrangement }\end{array}$ & $\begin{array}{l}\text { Transfer of activated } \\
\text { autologous T cells with the } \\
\text { graft is needed }\end{array}$ & $\begin{array}{l}\text { - Transferred cells increase the rate of graft rejection } \\
\text { - Cell injection prevents the observation of early events in } \\
\text { psoriasis pathogenesis }\end{array}$ \\
\hline AGR129 Mice & $\begin{array}{l}\text { - RAG-2(-)/(-) } \\
\text { - Impaired B \& T Lineages } \\
\text { - Deficiency of IFN- } \alpha \\
\text { - Deficiency of IFN- } \gamma\end{array}$ & $\begin{array}{l}\text { Injections of cells with the graft } \\
\text { is not mandatory }\end{array}$ & $\begin{array}{l}\text { - Lack of cell injection renders the model ideal to study early } \\
\text { events in psoriasis pathogenesis }\end{array}$ \\
\hline
\end{tabular}

Table 1: Characteristics of Xenotransplantation models in Psoriasis

\begin{tabular}{|c|c|c|}
\hline & Mild Psoriasis & Moderate to Severe Psoriasis \\
\hline First Line & $\begin{array}{l}\text { - Calcipotriol + Betametasone topical preparation } \\
\text { - } \quad \text { Vitamin D analogs (calcipotriol or calcitriol) }\end{array}$ & $\begin{array}{ll}\text { - } & \text { Acitretin + NB-UVB } \\
\text { - } & \text { NB-UVB + topical tazarotene gel or vitamin D analogs } \\
& \text { Acitretin + topical calcipotriol }\end{array}$ \\
\hline Second Line & $\begin{array}{l}\text { - Calcineurin inhibtors (tacrolimus or pimecrolimus) } \\
\text { in topical preparation }\end{array}$ & $\begin{array}{l}\text { - Increase the antirejection drug dose: tacrolimus }>\text { cyclosporine and } \\
\text { tacrolimus + mofetil micofenolate>azatioprine }\end{array}$ \\
\hline Third Line & $\begin{array}{l}\text { - Consider first line therapy of moderate to severe } \\
\text { psoriasis }\end{array}$ & $\begin{array}{ll}\text { - } & \text { TNF-blockers+ acitretin (if possible) } \\
\text { - } & \text { Ustekinumab } \\
\text { - } & \text { Apremilast } \\
\text { - } & \text { IL-17 blockers } \\
\text { MTX* }\end{array}$ \\
\hline
\end{tabular}

Abbreviations: NB-UVB: narrow band ultraviolet B, TNF: Tumor necrosis factor, IL: interleukin, MTX: methotrexate. *Avoid MTX in liver transplant and use with caution in kidney transpant.

Table 2: Guidelines in organ-transplanted patients with psoriasis.

Despite these obstacles, the National Psoriasis Foundation created an algorithm based on clinical experience and re-evaluation of literature (Table 2) [39].

For mild psoriasis, the first line therapy takes into consideration the topical approach with vitamin D analogues, with or without the combination of corticosteroids. However, the second-line treatment includes topical Calcineurin Inhibitors (CI), namely Tacrolimus and Pimecrolimus, and Tazarotene and Tar-based therapy [39].

Moderate to severe psoriasis remains a real matter of discussion due to the introduction of systemic therapy, which impacts the whole body that is already immune-compromised to withstand and transplanted organ [39].

First line therapy evaluates the synergic use of Acitretin plus narrowband ultraviolet therapy, especially in Fitzpatrick skin phenotypes III and VI, or NB-UVB alone, if oral Retinoids are contraindicated. The NB-UVB in the last case might be more effective with the topical application of Tazarotene gel $0.1 \%$ or Vitamin D3 analogs [39]. Oral Acitretin together with topical Calcipotriol might represent an alternative approach, to avoid severe dysfunction of the liver and kidneys along with uncontrolled hyperlipidemia [39].

The second line therapy includes anti-rejection medications, namely Cyclosporine, Mycophenolate Mofetil (MMF), Tacrolimus, or mTOR inhibitors [39]. The choice of the drug is also strictly dependent on the type of transplanted organ and a set of particular considerations as the following: Cyclosporine has to be avoided in renal recipients, Tacrolimus is preferred over Pimecrolimus and Cyclosporine, Tacrolimus + MMF is preferred over Azathioprine, and mTOR inhibitors should be switched after 6 months of stable transplanted and functional organ [39].

The third line therapies displayed the highest evidence with Etanercept that improves OTRs psoriasis without increasing the risk of malignancy, infections and loss of graft function [39]. Methotrexate was only assessed in one case report, however, its use should be carefully evaluated due to the cumulative toxicity in liver transplants and systemic toxicity in kidney transplants [39]. Other TNF blockers,
Apremilast, Ustekinumab and IL-17 blockers are mentioned only in the third line of treatment because of available case reports, although their usefulness was suggested by analyzing trials from literature on psoriatic patients [39]. A retrospective study of 16 adults with kidney transplants that underwent anti-rejection therapy plus TNF-blockers described the efficacy of this combination in curing concurrent chronic inflammatory diseases, as psoriasis. However, A high risk of subsequent infections and careful use in patients older than 50 years of age were underlined [40].

The only contraindication as a therapeutic agent in OTRs patients was Psoralen with UVA (PUVA) because of its well-documented side effects such as: highly increased risk of melanoma and non-melanoma skin cancers [41].

\section{Conclusions}

Stem cells abnormalities, their relation to peripheral blood cells and the increased number of psoriasis-related comorbidities highlight the multi-systemic inflammatory nature of this disease. Dysfunctions in bone marrow hematopoiesis might explain the abnormal activation of Th1-Th17 previously described in literature, offering at the same time a possible strategy to cure psoriasis in a safe and effective therapeutic model. However, a better understanding of the pathogenesis of psoriasis is mandatory to better design future trials regarding stem cells transplantation.

\section{Funding}

No funding sources

\section{Conflicts of Interest}

None

\section{Acknowledgement}

None

\section{References}

1. Boehncke WH, Schön MP (2015) Psoriasis. Lancet 386: 983-94. 
Citation: Damiani G, Berti E, Pigatto PDM, Franchi C, Asa'ad F, et al. (2018) Benchmarking Stem Cells and Transplantation in Psoriasis. J Stem Cell Res Ther 8: 416. doi: 10.4172/2157-7633.1000416

Page 4 of 4

2. Damiani G, Radaeli A, Olivini A (2016) Increased airway inflammation in patients with psoriasis. Br J Dermatol 175: 797-799.

3. Della Valle V, Maggioni M, Carrera C (2017) A mysterious abdominal pain during active psoriasis. Intern Emerg Med: 1765.

4. Conrad C, Gilliet M (2018) Psoriasis: from Pathogenesis to Targeted Therapies. Clin Rev Allergy Immunol 54: 102-113. [PubMed]

5. Malerba M, Damiani G, Radaeli A(2015) Narrow-band ultraviolet b phototherapy in psoriasis reduces pro-inflammatory cytokine levels and improves vitiligo and neutrophilic asthma. Br J Dermatol. 173: 1544-1545. [PubMed]

6. Eder L, Harvey P, Chandran V (2018) Gaps in Diagnosis and Treatment of Cardiovascular Risk Factors in Patients with Psoriatic Disease: An International Multicenter Study. J Rheumatol : 17039.[PubMed]

7. Fiore M, Leone S, Maraolo AE (2018) Liver Illness and Psoriatic Patients. BioMed Res Int : 3140983.[PubMed]

8. Malerba M, Radaeli A, Olivini A (2014) Exhaled nitric oxide as a biomarker in copd and related comorbidities," Biomed Res Int: 271918

9. Malerba M, Damiani G, Carpagnano G (2016) Values in Elderly People for Exhaled Nitric Oxide (VEPENO) study. Rejuvenation Res: 19: 233-238.

10. Damiani G, Franchi C, Pigatto P (2018) Outcomes assessment of hepatitis C virus-positive psoriatic patients treated using pegylated interferon in combination with ribavirin compared to new Direct-Acting Antiviral agents. World J Hepatol 10: 329-336.

11. Chen H, Niu JW, Ning HM (2016) Treatment of Psoriasis with Mesenchymal Stem Cells. Am J Med 129: e13-4. [PubMed]

12. Rezzani R, Rodella L, Favero G (2014) Attenuation of uva-induced alterations in nih3t3 dermal fibroblasts by melatonin. Br j Dermatol 170: 382-391. [PubMed]

13. Kaffenberger BH, Wong HK, Jarjour W, Andritsos LA (2013) Remission of psoriasis after allogeneic, but not autologous, hematopoietic stem-cell transplantation. J Am Acad Dermatol 68: 489-492.

14. Mele C, Salerno MP, Romagnoli J (2013) Complete clinical remission of psoriasis 6 months after renal transplantation. Transplant Proc 45: 2788-2789. [PubMed]

15. Sharpe PM, Ferguson MW (1998) Mesenchymal influences on epithelial differentiation in developing systems. J cell Sci Suppl 10: 195-230.

16. Campanati A, Orciani M, Consales V (2014) Characterization and profiling of immunomodulatory genes in resident mesenchymal stem cells reflect the Th1Th17/Th2 imbalance of psoriasis. Arch Dermatol Res 306: 915-920.

17. Charruyer A, Fong S, Vitcov GG (2017) Brief Report: Interleukin-17ADependent Asymmetric Stem Cell Divisions Are Increased in Human Psoriasis: A Mechanism Underlying Benign Hyperproliferation. Stem Cells 35: 2001 2007. [PubMed]

18. Jia HY, Shi Y, Luo LF (2016) Asymmetric stem cell division ensures sustained keratinocyte hyperproliferation inpsoriatic skin lesions. Int $\mathrm{J}$ Mol Med 37: 359-368.

19. Watarai A, Amoh $Y$, Maejima $H$ (2013) Nestin expression is increased in the suprabasal epidermal layer in psoriasis vulgaris. Acta Derm Venereol 93: 39-43

20. Chamberlein G, Fox J, Ashton B, Middleton J (2007) Concise review: Mesenchymal stem cells: their phenotype, differentiation capacity, immunological features, and potential of homing. Stem Cells 25: 2739-2749.

21. Hou R, Li J, Niu X (2017) Stem cells in psoriasis. J Dermatol Sci 86: 181-186.

22. Waterman RS, Tomchuck SL, Henkle SL, Betancourt AM (2010) A new mesenchymal stem cell (MSC) paradigm: polarization into a pro-inflammatory MSC1 or immunosuppressive MSC2 phenotype. PLoS One 5: e10088.

23. Xu C, Ren G, Cao G (2013) MiR-155 regulates immune modulatory properties of mesenchymal stem cells by targeting TAK1-binding protein 2. J Biol Chem 288: $11074-11079$

24. Orciani M, Campanati A, Salvolini E (2011) The mesenchymal stem cell profile in psoriasis. Br J Dermatol 165:585-592

25. Campanati A, Orciani M, Consales V (2014) Characterization and profiling of immunomodulatory genes in resident mesenchymal stem cells reflect the Th1 Th17/Th2 imbalance of psoriasis. Arch Dermatol Res 306: 915-920

26. Sah SK, Park KH, Yun CO (2016) Effects of human mesenchymal stem cells transduced with superoxide dismutase on imiquimod-induced psoriasis-like skin inflammation mice. Antiox Redox Signal 24:233-248

27. Zhang Z, Liu R, Yin G (2010) Differential cytokine secretion of cultured bone marrow stromal cells from patients with psoriasis and healthy volunteers. Eur J Dermatol 20: 49-53.

28. Liu RF, Li JQ, Hou RX (2015) Impact of BMMSCs from different sourceson proliferation pf CD34(+) cells. Genet Mol Res 14:474-482.

29. Hou R, Liu R, Niu X (2014) Biological characteristics and gene expression pattern of nibone marrow mesenchymal stem cells in patients with psoriasis. Eur J Dermatol 23:521-523.

30. Zhang Z, Yu Z, Tian P (2014) Differentially expressed genes identified by suppression subtractive hybridization in the bone-marrow hematopoietic stem cells of patients with psoriasis. Mol Med Rep 10: 479-485.

31. Nakajima K, Sano S (2017) Mouse models of psoriasis and their relevance. J Dermatol: 14112. [PubMed]

32. Hawkes JE, Adalsteinsson JA, Gudjonsson JE, Ward NL (2018) Research Techniques Made Simple: Murine Models of Human Psoriasis. J Invest Dermatol 138: e1-e8.

33. Di Domizio J, Conrad C, Gilliet M (2017) Xenotransplantation Model of Psoriasis. Methods Mol Biol. 1559: 83-90. [PubMed]

34. Daikeler T, Labopin M, Ruggeri A (2013) New autoimmune diseases after cord blood transplantation: a retrospective study of EUROCORDand the Autoimmune Disease Working Party of the European Group for Blood and Marrow Transplantation. Blood 121: 1059-1064.

35. Sotiropoulos GC, Radtke A, Molmenti EP (2011) Long-term follow-up after righ hepatectomy for adult living donation and attitudes toward the procedure. Ann Surg 254: 694-700. [PubMed]

36. Dedemadi G, Koukoulaki M, Vougas V (2016) Generalized Pustular Psoriasis (Von Zumbusch Type) Following Renal Transplant: A Case Report. Exp Clin Transplant: 0036. [PubMed]

37. Mori J, Kakihana K, Ohashi K (2012) Sustained remission of psoriasis vulgaris after allogeneic bone marrow transplantation. $\mathrm{Br} \mathrm{J}$ Haematol 159:121.

38. Mabuchi T, Kojima T, Yamaoka H (2012) Development of psoriasis 10 years after allogeneic hematopoietic cell transplantation from non-psoriatic donor: Further evidences for genetics and immunopathogenesis of psoriasis. J Dermatol 39:1072-1074.

39. Prussick R, Wu JJ, Armstrong AW (2017) Psoriasis in a solid organ transplan patients: best practice recommendations from the Medical Board of the National Psoriasis Foundation. J Dermatolog Treat 24: 1-5.

40. Garrouste C, Anglicheau D, Kamar N (2016) Anti-TNFa therapy for chronic inflammatory disease in kidney transplant recipients: Clinical outcomes. Medicine (Baltimore) 95: e5108. [PubMed]

41. Archier E, Devaux S, Castela E (2012) Carcinogenic risks of psoralen UV-A therapy and narrowband UV-B therapy in chronic plaque psoriasis: a systematic literature review. J Eur Acad Dermatol Venereol 26 Suppl 3: 22-31. [PubMed]. 